Revista Eletrônica do Mestrado em Educação Ambienta]

Programa de Pós-Graduação em Educação Ambiental

\title{
(Eco)Narrativa de uma caminhada na floresta australiana ${ }^{1}$
}

\author{
Valéria Ghisloti Iared $^{2}$ \\ Universidade Federal do Paraná \\ https://orcid.org/0000-0002-1082-9870
}

Resumo: Atualmente, alguns estudiosos do campo da educação ambiental vêm se debruçando sobre o despertar das apreensões estéticas e afetividades sobre a natureza. $\mathrm{O}$ manuscrito apresenta uma vivência na natureza por meio de uma (eco)narrativa e discute as interações corporais e multissensoriais entre humanos não humanos durante essa experiência. A partir disso, outros aspectos que vêm sendo pontuados em pensamentos filosóficos emergentes (como novo materialismo, teoria não representacional, ecofenomelogia) são colocadas em diálogo com o objetivo de contribuir com a tríade ontologia $\sim$ epistemologia $\sim$ metodologia na pesquisa. Particularmente, o artigo busca contribuir com investigações que têm por intuito legitimar as afetividades, emoções e não humanos em uma perspectiva menos antropocêntrica.

Palavras-chave: pós-humano; experiência estética; epistemologias ecológicas.

\section{(Eco)Narrativa de una caminada en la floresta australiana}

Resumen: Actualmente, algunos académicos en el campo de la educación ambiental han estado abordando el despertar de aprensiones estéticas y afectividades sobre la naturaleza. El manuscrito presenta una experiencia en la naturaleza a través de una (eco)narración y discute las interacciones corporales y multisensoriales entre humanos $\sim$ no humanos durante esta experiencia. A partir de esto, otros aspectos que han sido puntuados en los pensamientos filosóficos emergentes (como el nuevo materialismo, la teoría no representativa, la ecophenomelogy) se colocan en diálogo con el objetivo de contribuir a la tríada ontología epistemología metodología en la investigación. Particularmente, el artículo busca contribuir a las investigaciones que apuntan a legitimar afectividades, emociones y no humanos desde una perspectiva menos antropocéntrica.

Palabras clave: posthuman; experiencia estética; epistemologías ecológicas.

\footnotetext{
${ }^{1}$ Esse trabalho foi previamente apresentado na XIII Reunião de Antropologia do Mercosul em julho de 2019 em Porto Alegre - RS no formato de trabalho completo. A versão aqui apresentada incorporou as sugestões do Grupo de Trabalho 57 - Experimentações etnográficas acerca das associações entre humanos e não-humanos.

${ }^{2}$ Graduada em Ciências Biológicas pela UFSCar (2006). Doutora em Ciências (UFSCar). Professora adjunta no Departamento de Biodiversidade/ UFPR. e-mail: valiared@gmail.com.
}

Rev. Eletrônica Mestr. Educ. Ambient. Rio Grande, v. 36, n. 3, p. 198-212, set./dez. 2019.

E-ISSN 1517-1256 


\title{
(Eco)Narrative of a walk in the australian forest
}

\begin{abstract}
Currently, some scholars in the field of environmental education have been addressing the awakening of aesthetic apprehensions and affectivities about nature. The manuscript presents an experience in nature through a (echo)narrative and discusses the bodily and multisensory interactions between humans $\sim$ nonhumans during this experience. From this, other aspects that have been punctuated in emerging philosophical thoughts (such as new materialism, nonrepresentational theory, ecophenomelogy) are put into dialogue with the aim of contributing to the triad ontology $\sim$ epistemology $\sim$ methodology in the research. Particularly, the article seeks to contribute to investigations that aim to legitimize affectivities, emotions and non-humans from a less anthropocentric perspective.
\end{abstract}

Key words: posthuman; aesthetic experience; ecological epistemologies.

\section{INTRODUÇÃO}

A pesquisa nas ciências sociais e humanas (e consequentemente na educação) vem sendo marcada por uma série de questionamentos no que se refere aos métodos de coleta e análise de dados (BELSEY, 2002; DENZIN; LINCOLN; 2006; FOX; ALLDRED, 2018; LATHER; PIERRE, 2013). Igualmente, o campo da pesquisa em educação ambiental foi e é marcado por esses posicionamentos em relação a coerência entre a tríade ontologia epistemologia $\sim$ metodologia $^{3} \quad$ (PAYNE, 2009; ROBOTTOM; HART, 1993), o que vem se acentuando com as emergências de alguns movimentos "pós" (pós-moderno, pósestruturalismo, pós-humano).

Essas viradas nos convidam a responder e examinar nossas preconcepções e posicionamentos nas transições pós-críticas na pesquisa em educação ambiental (HART, 2005, 2013). O termo pós-crítico usado por Hart $(2005,2013)$ e Payne (2016) amplia a noção de "crítico" usado na modernidade. Sob o risco de desvelar a complexidade da problemática ambiental e se prender na armadilha paradigmática (GUIMARÃES, 2011) dos enredos da modernidade, do neoliberalismo, da pós-modernidade e do discurso do desenvolvimento sustentável, o ambientalismo precisa ser apropriado com cautela (PAYNE, 2016). Segundo Hart (2005, 2013) e Payne (2016), com o surgimento dos movimentos das "viradas" - virada corporal (SHEETS-JOHNSTONE, 1999) e a virada afetiva (CLOUGH; HALLEY, 2007) - emergiu uma série de teorias "menos antropocêntricas" ou pós-humanas (BRAIDOTTI, 2013) que reanimou e revitalizou conceitos, processos investigativos, metodologias e operações analíticas que diferem e

\footnotetext{
${ }^{3}$ A opção pelo uso do til ( ) reforça a proposição da conexão efetiva entre os significados dessas palavras. Rev. Eletrônica Mestr. Educ. Ambient. Rio Grande, v. 36, n. 3, p. 198-212, set./dez. 2019. E-ISSN 1517-1256
} 
ampliam as teorias tradicionais e teorias críticas que as precederam. As pesquisas póscríticas na educação ambiental têm a potencialidade de refletir sobre a tensão ontologia epistemologia metodologia já que são interpretadas pelo paradigma ecocêntrico (PAYNE, 2016).

Conforme Iared, Oliveira e Payne (2016) demonstram, essas derivações teóricas e metodológicas mais contemporâneas são embasadas na concepção de corpo como carne do mundo de Mearleu-Ponty (2007), o qual está imbricado como sensível. Para o filósofo, movimento percepção criação de sentido não tem dissociação espaço temporal. Essa noção de um corpo sensitivo e sinestésico que se move engajado no mundo foi, entre outros referenciais, determinante para metodologias que preconizam pela compreensão do sensível e da multissensorialidade nas interações com o ambiente (INGOLD; VERGUNST, 2008; PINK, 2009).

Segundo Conolly (2010), Mearleu-Ponty revisou sua concepção de sujeito e de natureza não - humana em suas últimas cartas ao instigar a identidade entre humanos e não humanos. Para Conolly (2010), sob a perspectiva fenomenológica, existem afinidades entre seres humanos, os outros seres vivos e os sistemas físicos, logo, há materialidade na experiência. De fato, alguns fenomenólogos contemporâneos avançaram nas proposições sobre a compreensão da experiência estética da natureza e isso vem sendo pautado na pesquisa em educação ambiental (IARED; OLIVEIRA; PAYNE, 2016).

Ao colocar em diálogo a fenomenologia com a literatura das "viradas" (afetiva/ corporal/ ontológica/ paradigmática), Brown e Toadvine (2003) optam pelo termo (eco)fenomenologia para enfatizar a incorporação do mundo mais que humano ou dos não humanos na experiência do mundo sensível. Essa colaboração entre a fenomenologia e os princípios da ecologia profunda e do ambientalismo visa erradicar os pressupostos antropocêntricos e propor alternativas para ampliar o campo teórico desse referencial. Em consonância com a (eco)fenomenologia, Lotz-Sisitka et al. (2015) optam pelo termo fenomenologia crítica ao dizer que os diferentes movimentos como Animismo, Antroposofia e educação estética reivindicam a necessidade de transgredir os limites entre os mundos interior e exterior e as dicotomias do paradigma ocidental, buscando reavivar as sensibilidades intuitivas como forma de motivar o engajamento participativo, o qual tem relação com uma sociedade verdadeiramente democrática e a cidadania ativa nas decisões locais.

Rev. Eletrônica Mestr. Educ. Ambient. Rio Grande, v. 36, n. 3, p. 198-212, set./dez. 2019. E-ISSN 1517-1256 
Como alternativa a essa provocação, o walking ethnography ${ }^{4}$ (INGOLD; VERGUNST, 2008) ou a etnografia sensorial - em inglês, sensory ethnography- (PINK, 2009) ou investigações móveis vêm sendo apropriadas em estudos fenomenológicos. As práticas corporais e sensoriais no meio ambiente merecem um olhar investigativo cuidadoso uma vez que assumimos um referencial ontológico e epistemológico que se pauta na não dissociação entre estética ética política como diria Payne (2014) e Rodrigues (2015) ou movimento percepção de Ingold (2011, 2000) e Pink (2009).

Para Pink (2009) e Ingold (2014), a etnografia sensorial ou etnografia em movimento não se restringe às novas maneiras de se fazer pesquisa, isto é, a autora e o autor não privilegiam nenhum protocolo de coleta e análise de dados que seguem normas prescritivas. Iared e Oliveira (2017) afirmam que os estudos que se pautam nessa perspectiva aplicam diversos instrumentos de pesquisa que podem ser adaptados segundo o contexto, público e questão da investigação. Segundo Pink (2009) e Ingold (2014), a etnografia precisa se reinventar ao explorar explicitamente a percepção sensorial e incorporar técnicas de coleta, de análise e representação dos dados que sejam mais colaborativas e participativas. Isso se configura não apenas como um novo método, mas como um compromisso ontológico para com a pesquisa (INGOLD, 2014).

Alguns estudos em educação ambiental têm incorporado as caminhadas enquanto o cerne da coleta e análise de dados. Por exemplo, Iared (2018) realizou caminhadas no Cerrado para apreensão da experiência estética dos participantes, enquanto Payne et al. (2018) se propuseram a estudar as afetividades durante uma caminhada na Mata Atlântica. Também, nesse contexto, Duarte, Sato e Pazos (2018) buscaram compreender os aprendizados que podem emergir durante as travessias na Serra do Espinhaço em Minas Gerais.

O presente ensaio objetiva apresentar brevemente uma experiência estética da natureza por meio de uma (eco)narrativa com o intuito de oferecer uma alternativa metodológica nas pesquisas em educação ambiental que tenham por objetivo abordar as afetividades e as emoções. As (eco)narrativas (PAYNE, 2013) são uma sugestão de relato dos dados de um ensaio empírico. Por meio delas, a ideia de representação da experiência é descentralizada, dando-se ênfase para ao testemunho de um engajamento corporal e afetivo. Jickling (2009) também recorre a uma narrativa como uma forma de resistência às separações de mente $\sim$ corpo e mente $\sim$ paisagem, reconhecendo que as construções sociais

\footnotetext{
${ }^{4}$ No Brasil, temos optado pelo termo etnografia em movimento.

Rev. Eletrônica Mestr. Educ. Ambient. Rio Grande, v. 36, n. 3, p. 198-212, set./dez. 2019. E-ISSN 1517-1256
} 
preexistentes à vivência relatada influenciaram o engajamento sensorial. A opção por esse formato advém da busca da coerência com o referencial teórico metodológico.

Ao trazer essas discussões para esse manuscrito, optamos por desviar da sequência tradicional de redação de um artigo científico. Para tanto, uma (eco)narrativa (equivalente ao tópico "Resultados") de uma caminhada em uma floresta australiana (Figuras 1 e 2) será apresentada para, então, ser descrito no mesmo item, os procedimentos de coleta e análise da (eco)narrativa. O último tópico do estudo encerra o manuscrito reafirmando a importância de aprofundar esse campo de estudo buscando a intrínseca relação entre ontologia $\sim$ epistemologia $\sim$ metodologia e a relevância científica $\sim$ social da pesquisa.

Figuras 1 e 2 - Floresta australiana como lugar da experiência estética descrita na (eco)narrativa
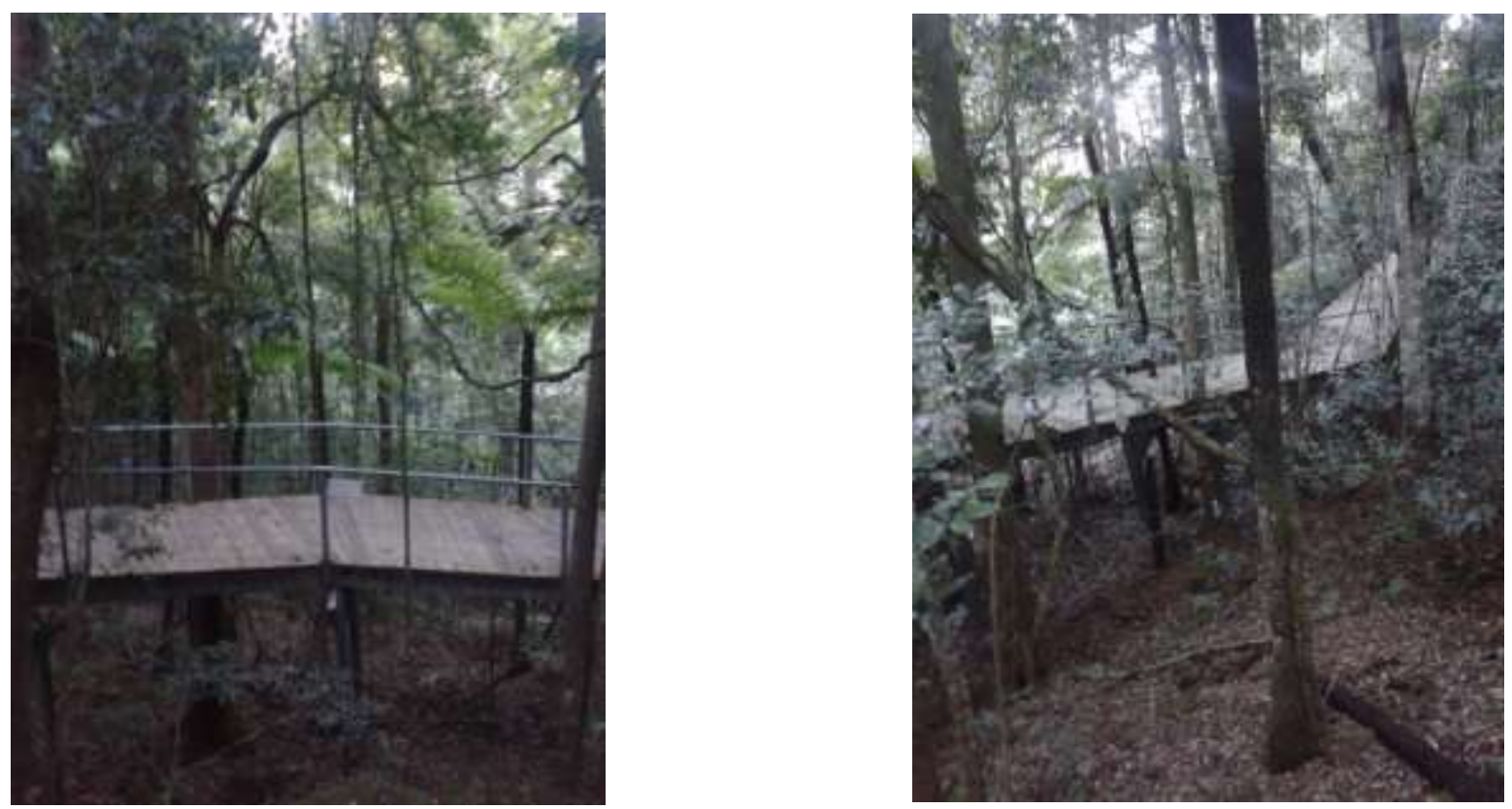

Fonte: autoria própria (2014)

\section{(Eco)narrativa}

Era junho de 2014, estávamos no inverno australiano, mesmo assim, era um dia agradável em Sydney com temperatura baixa, mas o sol cumpria seu papel em aquecer os nossos corpos. Eu estava explodindo de felicidade! Fazia nove meses que havia me mudado para a Austrália e minha família estava me visitando. Era como se estivesse vivendo um sonho. Meus pais nunca tinham saído do país e quando saem, vão para o 
outro lado do mundo?! As lágrimas me vêm aos olhos quando lembro desses dias. Eu queria desbravar as belezas da Austrália junto com eles.

Acordamos cedo, tinha comentado que valia a pena passarmos o dia todo naquele passeio. A "Blue Mountains" era um dos locais mais bonitos da Austrália. Então, lá fomos nós, eu, meu pai, minha mãe e meu irmão, em uma viagem de poucas horas para chegar nesse famoso local turístico. Optamos por pegar uma van junto com uma agência de viagem, porque além de mais cômodo para o deslocamento, havia um guia para ir explicando. Durante a viagem, paramos em alguns pontos, mas não demorou muito para chegar nas populares "Three Sisters”. Era uma paisagem convidativa! Nos demoramos nela como espectadores de uma das pinturas mais acolhedoras que já havíamos visto. Inspiramos, expiramos, respiramos ali por alguns minutos até que... nos demos conta que havíamos nos afastado e nos perdido do restante do grupo! O guia tinha avisado que daquele local iríamos pegar um bonde ou teleférico para chegar em um vale.

$N a$ tentativa de encontrar o grupo, fomos para o local de saída do teleférico. $O$ grupo não estava lá. O nervosismo tomou conta dos meus pais e, por consequência, eu e meu irmão também ficamos ansiosos em vê-los aflitos. Como estávamos com os tickets de entrada, decidimos pegar o teleférico e descer para o vale. O nervosismo só aumentou quando percebemos que estávamos realmente sozinhos. A descida era íngreme, a sensação era que estávamos descendo para um buraco no meio das montanhas e esse caminho despertou o medo na minha mãe que segurava forte nas estruturas de metal daquele bonde aéreo.

Após alguns minutos, o teleférico chegou no vale... e desembarcamos em uma robusta floresta australiana. Nos vimos como os únicos seres humanos cercados de não humanos e todos nós compúnhamos uma paisagem exuberante e imponente. Estávamos literalmente mergulhados e misturados com a floresta!

$O$ nervosismo, o medo, a aflição e a ansiedade cessaram. A respiração ofegante deu lugar a serenidade. $O$ andar era lento. Passos curtos e olhares voltados para o dossel da floresta. Tomou conta o encantamento! Tomou conta o silêncio! Tomou conta a floresta! Andávamos cada um no seu ritmo. A caminhada mansa, o sorriso contemplativo e a respiração tênue eram pontos em comum entre nós quatro, ao mesmo tempo que, a singularidade da experiência era evidente. Cada um optou por um percurso e um ritmo. Meu irmão se virou, avistou minha mãe parada, quieta, mais distante de onde nós estávamos e questionou se estava tudo bem. Ela simplesmente respondeu: “- estou rezando".

Rev. Eetrônica Mestr. Educ. Ambient. Rio Grande, v. 36, n. 3, p. 198-212, set./dez. 2019. E-ISSN 1517-1256 
Não sei precisar o tempo que ficamos ali, mas o tempo Kairós nos dizia para não nos preocuparmos com o implacável Chronos e nos ensinava sobre a leveza $e$ despojamento do momento. O retorno para o topo da montanha assumiu outro tom durante a subida no teleférico. O brilho no olhar, a fala mansa e a respiração calma oportunizaram um clima descontraído, de risadas, deslumbre e agradecimento por termos compartilhado juntos aquela paisagem que nunca mais saiu de nossas memórias!

\section{O movimento, a experiência estética e a (eco)narrativa}

Conforme exposto anteriormente, uma revisão bibliográfica, realizada por Iared e Oliveira (2017), indicou que não há um procedimento engessado nessa metodologia. Os diferentes artigos apontaram diferentes propostas: uso ou não de gravador ou câmeras, caminhadas em grupo ou somente um participante da pesquisa, presença de roteiro a ser preenchido ou momento da coleta de dados completamente conduzido pelos participantes da pesquisa, entre outras nuances que flexibilizam a metodologia.

No entanto, as próprias autoras pontuam que, embora sigam etapas divergentes, todos os estudos têm por princípio a apreensão das dimensões sensoriais e afetivas das pessoas e o engajamento da/o própria/o pesquisador/a na experiência estética testemunhando a vivência em contraposição a descrição por meio de uma entrevista ou outro tipo de representação. Outro ponto também discutido nesses estudos é a ausência do estar frente a frente com a/o colaborador/a da investigação, o que, geralmente, causa algum tipo de constrangimento, desconforto e inquietação em quem se sente alvo de uma questão de pesquisa. A espontaneidade do movimento, seja na caminhada, ou em um passeio de barco ou de bicicleta ou em outra atividade em que ambos (pesquisador/a e participante) se envolvam diretamente no momento da coleta, favorece uma atmosfera mais amistosa entre pesquisadoras/es e participantes.

No caso deste relato, a coleta de dados não foi premeditada, ou seja, planejada como um momento de coleta de dados para uma pesquisa específica. O/A pesquisador/a não fez esse passeio com a intencionalidade de coletar os dados. No entanto, à medida que o dia foi se desvelando e ao perceber que estava vivenciando uma experiência estética da paisagem australiana, surgiu a opção por aproveitá-lo como um aprendizado. Dessa maneira, logo após o término da caminhada, foi gravada uma contação detalhada sobre a experiência. A construção do texto aqui apresentado foi feita com base nessa gravação e nas fotos capturadas durante a vivência. A elaboração da (eco)narrativa foi demorada, Rev. Eetrônica Mestr. Educ. Ambient. Rio Grande, v. 36, n. 3, p. 198-212, set./dez. 2019. E-ISSN 1517-1256 
sendo o texto revisado diversas vezes na tentativa de incorporar a arte e a poesia na apresentação do que foi vivido. Ao trabalhar com a interface arte, experiência estética da natureza e fenomenologia, estamos corroborando que o presente estudo não tem por pretensão explicar a experiência e sim expressar o que foi testemunhado.

Nessa tentativa de apresentar a vivência, tal metodologia oportuniza a expansão da realidade para além da consciência humana e suas línguas (PAYNE, 2016). Para o autor, o não humano ou o mais que humano ainda são "inacessíveis e afetivamente "não representacionais', sejam eles em políticas, currículo, pedagogia e pesquisas" (PAYNE, 2016, p. 171, tradução nossa). Thrift (2008) e McCormack (2013) dissertam sobre a teoria não representacional argumentando que os espaços afetivos não podem ser representados cognitivamente, isto é, "esses espaços têm uma qualidade que não pode necessariamente ser compreendida ou avaliada através de um modelo representacional de pensamento" (McCORMACK, 2013, p.04, tradução nossa). Essa perspectiva assume o engajamento corporal e experiencial e valoriza o processo afetivo que precede a consciência e a reflexão, não objetivando a representação da vivência, mas, sim, a sua potencialidade em gerar diferença, divergência e criação (McCORMACK, 2013).

Esse ponto é fundamental na experiência narrada no presente manuscrito. Ao perguntar para minha família sobre a viagem e os passeios, elas/es citam o vale que conheceram dizendo “- desci em uma floresta australiana espetacular!". No entanto, outras nuances fundamentais da vivência não aparecem, como, por exemplo, o fato da minha mãe ter parado e rezado. Naquele espaço tempo, ela se viu na presença de algo tão sublime e transcendente que se igualava a algo divino. Ela jamais relatou o fato de ter sentido uma imensa vontade de expressar sua plenitude da experiência estética por meio de uma oração.

A natureza como lugar sagrado é discutida por Carvalho e Steil (2008). A autora e o autor discorrem sobre a convergência entre os universos das ciências ambientais e da espiritualidade no que diz respeito ao cuidado tanto do corpo e da alma como do ambiente. Nesse sentido, a reconexão com a natureza passa a integrar as práticas e crenças religiosas e "remete à realização de um bem-estar físico, mental e espiritual que torna indissociável a saúde do planeta e do indivíduo" (CARVALHO; STEIL, 2008, p. 03). Ou seja, para a autora e o autor, é possível identificar uma dimensão pedagógica na experiência do sagrado que se expressa na ressignificação das sensibilidades em relação à natureza, constituindo-se como nova modalidade de vincular sujeitos ecológicos à paisagem.

Para Katz (2000), muitas investigações analisam o que as pessoas falam sobre seus sentimentos por métodos como questionários, entrevistas e outros instrumentos, como se a Rev. Eletrônica Mestr. Educ. Ambient. Rio Grande, v. 36, n. 3, p. 198-212, set./dez. 2019. E-ISSN 1517-1256 
fonte de emoções tivesse origem em algum lugar fora do corpo. $\mathrm{O}$ autor debate sobre a tradicional maneira de se analisar a experiência emocional por meio de textos ou números dizendo que são apenas forma de representação e não captam a emoção em si mesma. Em uma edição especial do periódico Digital Creativity, Roudavskia e McCormack (2016) incentivaram abordagens inovadoras seguindo a opção por uma aproximação menos antropocêntrica da agência, autonomia, subjetividade, práticas sociais e tecnologias que substituíssem as formas tradicionais de escrita acadêmica. Diálogos, conversas, peças de teatro, pinturas, desenhos, fotografias, meditação, poesias e mímicas podem ser explorados ao enfrentar o desafio de conceber uma criatividade pós-humana.

Em seu livro Refrains for moving bodies, McCormack (2013) explora, justamente, a qualidade do espaço afetivo gerado para e por corpos em movimento, isto é, a relação entre o movimento corporal e o espaço é mais do que física. Apesar do aumento da discussão sobre a virada afetiva (CLOUGH; HALLEY, 2007), a afetuosidade ainda é subteorizada e sub-representada na Academia, no currículo, nas políticas públicas e na práxis pedagógica (PAYNE, 2016). Para McCormack (2013), as qualidades afetivas são capturadas pelo corpo sensível e se relacionam com questões da emoção, humor e sentimentos. Essas qualidades da vida cotidiana podem ser exploradas de diversas maneiras sendo que os corpos engajados no mundo sensível são fundamentais para esta abordagem:

um dos principais pontos de vista emergentes da virada afetiva é que o afeto não está, de forma alguma, confinado ou contido no limite físico dos corpos. Afetar é, em vez disso, melhor concebido como um campo distribuído e difuso de intensidades, circulando dentro, mas também se movendo além e ao redor dos corpos. Ao mesmo tempo, o movimento dos corpos gera distúrbios e perturbações que transformam a intensidade e atingem esse campo. No processo, os corpos participam da geração de espaços afetivos: espaços cujas qualidades e consistências são vagas, mas percebidas, embora mal, como uma distinta tonalidade afetiva, humor ou atmosfera" (McCORMACK, 2013, p.03, tradução nossa).

Em outras palavras, McCormack (2013) defende que o corpo imbricado no espaço responde afetivamente ao mundo. De fato, isso foi percebido no presente estudo quando desembarcamos na floresta: o movimento do corpo influencia e é influenciado pela robusta paisagem - Passos curtos e olhares voltados para o dossel da floresta. Tomou conta o encantamento! Tomou conta o silêncio! Tomou conta a floresta! Andávamos cada um no seu ritmo. A caminhada mansa, o sorriso contemplativo e a respiração tênue eram pontos 
em comum entre nós quatro, ao mesmo tempo que a singularidade da experiência era evidente - trecho da (eco)narrativa.

Em consonância, Ingold (2011) diz que os organismos (humanos não humanos) não podem ser situados ou localizados em uma paisagem como se seus corpos tivessem um invólucro. Pelo contrário, o habitar o ambiente acontece no movimento, ou seja, a experiência está entrelaçada na malha de fluxos dos materiais (vento, temperatura, cores, cheiros, texturas, sons, histórias, memórias, etc). A sincronização entre todas essas materialidades constitui o fluxo da vida e daí advém a indissociabilidade entre cultura natureza e humanos não humanos.

Para Thoreau, filósofo norte-americano que viveu há aproximadamente 200 anos, essas experiências de fluxo fundem indivíduo e ação de maneira "que mente e mundo se integram, como que anulando as perspectivas usuais de afastamento e exterioridade adotadas pela mente inquieta, que julga "de fora" aquilo que vivenciamos" (WILLIGES, 2018, p.06). Para o filósofo, a concepção do bem-viver envolve afetividade e experiências estéticas na natureza, as quais não são frequentes no nosso cotidiano agitado. Intrigante pensar como as dicotomias e o modelo hegemônico de sociedade vêm sendo perpetuados e questionados há tempos.

Ao tomar como princípio a agência não humana e a materialidade do não humanos ou do mundo mais que humano, o pós-humanismo preconiza uma virada ontológica. Rodrigues (2015) e Payne (2014) sustentam a necessidade de uma desconstrução/reconstrução fenomenológica em processos educativos críticos, especialmente potencializadas em aprendizagens experienciais. Para tanto, os autores enfocam no lazer vagabundo (vagabonding, em inglês) para uma vivência corporal no ambiente que põe em suspensão o conforto, permitindo fluir a estranheza $\mathrm{e}$ as perturbações. Ou seja, talvez, a maior potencialidade de um lazer vagabundo seja, por meio da vivência perceptiva/sensorial com o ambiente, des/reconstruir certos elementos socialmente naturalizados.

$\mathrm{Na}$ experiência apresentada, o ritmo da vivência estética se deu pelos chamados refrãos dos corpos em movimento (McCORMACK, 2013) com momentos de nervosismo, inquietação, incômodo e aflição alternando com o encantamento, serenidade, mansidão e, até a sensação de estar testemunhando algo divino. Segundo Payne (2014) e Rodrigues (2015), esse processo de desconstrução/ reconstrução fenomenológica cria possibilidades de discussão dos aspectos estéticos $\sim$ éticos $\sim$ políticos na relação sociedade $\sim$ natureza mundo.

Rev. Eletrônica Mestr. Educ. Ambient. Rio Grande, v. 36, n. 3, p. 198-212, set./dez. 2019. E-ISSN 1517-1256 
Assim, incluir as "micro" narrativas dos sujeitos (PAYNE, 2014) é dar voz ao fluxo de afetos e, consequentemente o meio pelo qual as vidas, as sociedades e a história se desdobram. A quantidade e qualidade das interações afetivas criam capacidades para emancipação e transformação social (FOX, 2015), logo merecem ser ampliadas e aprofundadas nas investigações pós-críticas. Não obstante, Jickling (2009) considera que valorizar a aprendizagem experiencial não é negar ou abandonar os outros saberes convencionalmente propiciados pelas ciências. Também, não sugere que a compreensão emocional seja suficiente, mas acrescenta dimensões vitais à aprendizagem e, portanto, não deveria ser marginalizada ou separada dos objetivos centrais da educação.

A experiência, nesse presente estudo, foi uma apreensão da materialidade sensível da natureza e não uma representação de algo distante, fora de um corpo sinestésico engajado no mundo. Logo, torna-se difícil pensar no processo de experimentar como envolvendo a atividade de uma mente representando (internamente) os detalhes de um ambiente externo (MCCORMACK, 2013). Também, recusa-se a separação de um sujeito percebido e um objeto perceptivo e, ainda, de um/a pesquisador/a distante da vivência imbricada. Dessa maneira, muitas/estudiosas/os das mais diversas áreas (geografia, artes, antropologia e educação) têm se apropriado dos estudos móveis. Particularmente, para a educação ambiental, a metodologia parece trazer uma luz sobre a importância de abordar intencionalmente na pesquisa e na prática a materialidade do mundo mais que humano.

Por fim, argumentamos pela dimensão pedagógica dessa perspectiva e que se revela nesse estudo no qual todos os engajados na experiência estão entrelaçados pelo processo de aprendizagem. Ingold (2017), em sua obra Anthropology and/as Education, argumenta sobre a equivalência entre esses dois campos do saber diluindo a dicotomia entre pesquisador/a - pesquisado/a ou observador/a - objeto de pesquisa. Nesse sentido, ele propõe a noção de correspondência na qual ao invés de fragmentações ou territórios de estudo, temos uma malha de fluxos, ou seja, um emaranhado de linhas de interesse que se correspondem. Para ele, a observação participante também é correspondência já que estamos juntos com os outros nos movimentos de exposição à experiência. Para o autor, a educação expõe, ou seja, abre caminhos para novas descobertas e conhecimentos.

\section{REFLEXÕES A PARTIR DA EXPERIÊNCIA}

A metodologia abordada no ensaio teórico é uma proposta que não encerra outros desafios que ainda existem no campo da pesquisa da educação e, por consequência, da Rev. Eletrônica Mestr. Educ. Ambient. Rio Grande, v. 36, n. 3, p. 198-212, set./dez. 2019. 
educação ambiental. Um desses entraves, muito discutidos atualmente, é em relação às múltiplas teorias de análise que podem ser aplicadas, por exemplo, para o mesmo conjunto de dados (JACKSON; MAZZEI, 2012). Em concordância com essas discussões no campo das ciências sociais e humanas, Fox e Alldred (2018) pontuam que qualquer método de coleta de dados possui benefícios e inconvenientes e, certamente, essa não pode ser colocada como superior às outras.

A corrente filosófica do novo materialismo e pós-humanismo representam desafios para a ontologia $\sim$ epistemologia $\sim$ metodologia que sustenta muitas pesquisas qualitativas, com foco em ações e vozes humanas e interpretações dessas vozes e ações. Dentro dessas novas tensões acerca da investigação pós-crítica, algumas/ns autoras/es como Lather e Pierre (2013) vem defendendo a pesquisa pós-qualitativa (post-qualitative research, em inglês) que se propõe a ir além do foco humanista e de suas formas convencionais de métodos de coleta e análise de dados.

$\mathrm{O}$ presente relato discorre sobre uma possibilidade que parece ser coerente com a atual corrente filosófica do novo materialismo e pós-humanismo que preconizam uma ontologia plana (em inglês, flat ontology) a qual repensa/ reinventa/ reanima/ revitaliza as relações afetivas $\sim$ éticas $\sim$ políticas entre seres humanos não-humanos provocadas por uma disposição menos antropocêntrica na pesquisa, na prática e, não menos importante, nos processos de formulação de políticas públicas.

Em uma esfera mais "macro", McKenzie (2017) sugere que as afetividades influenciam as transformações da política ao longo do tempo e do espaço, explicando porque certas políticas são atraentes ou necessárias em momentos diferentes, ou porque os atores são motivados a defender ou adotar políticas específicas, ou quais sentimentos são mobilizados para encorajar o engajamento político, "em outras palavras, o que nos move de forma coletiva e individual também é importante para o que move a política" (p. 188, tradução nossa). Nesse contexto, lembramos a experiência da filosofia do "Bem Viver" de povos indígenas que acabaram por alcançar o patamar das políticas públicas na Bolívia e no Equador e se tornou um exemplo significativo de construção de uma outra proposta de se relacionar com o ambiente, tarefa tão cara para o campo da pesquisa e da prática em educação ambiental.

\section{REFERENCIAS}


BELSEY, Catherine. Poststructuralis m: a very short introduction. New York: Oxford University Press, 2002.

BRAIDOTTI, Rose. The posthuman. Malden: Polity Press, 2013.

BROWN, Charles; TOADVINE, Ted. Eco-Phenomenology: back to the earth itself. Albany: State University of New York Press, 2003.

CARVALHO, Isabel Cristina Moura; STEIL, Carlos Alberto. A sacralização da natureza e a 'naturalização' do sagrado aportes teóricos para a compreensão dos entrecruzamentos entre saúde, ecologia e espiritualidade. Ambiente \& Sociedade, v. XI, n. 2, p. 01-17, 2008.

CLOUGH, Patricia Ticineto; HALLEY, Jean. (eds). The affective turn: theorizing the social. Durham: Duke University Press, 2007.

CONNOLLY, William. Materiliaties of experience. In: COOLE, Diana; FROST, Samantha. (eds). New materialisms: ontology, agency, and politics. Durham: Duke University Press, 2010. p. 178-200.

DENZIN, Norman; LINCOLN, Yvonna. O planejamento da pesquisa qualitativa teorias e abordagens. $2^{\mathrm{a}}$ ed., Porto Alegre: Artmed, 2006.

DUARTE, Júlio Corrêa de Resende; SATO, Michèle; PAZOS, Araceli Serantes. A educação ambiental do caminhar. Revista Eletrônica Mestrado em Educação Ambiental, v. 35, n. 3, p. 94-113, 2018.

FOX, Nick. Emotions, affects and the production of social life. British Journal of Sociology, v. 66, n. 2, p. 301-318, 2015.

FOX, Nick; ALLDRED, Pam. Mixed methods, materialism and the micropolitics of the research-assemblage. International Journal of Social Research Methodology, v. 21, n. 2, p. 191-294, 2018.

GUIMARÃES, Mauro. Armadilha paradigmática na educação ambiental. In: LOUREIRO, Carlos Frederico.; LAYRARGUES, Philippe Pomier.; CASTRO, Ronaldo Souza de. (Orgs.). Pensamento complexo, dialética e educação ambiental. 2 ed., São Paulo: Cortez, 2011, p.11-29.

HART, Paul. Preconceptions and positionings: can we see ourselves within our own terrain? In: STEVENSON, Robert; BRODY, Michael; DILLON, Justin; WALS, Arjen. International Handbook of Research on Environmental Education. New York: Routledge Publishers, 2013, p. 507-510.

HART, Paul. Transitions in thought and practice: links, divergences, and contradictions in post-critical inquiry. Environmental Education Research, v. 11, n. 4, p. 391-400, 2005.

IARED, Valéria Ghisloti. Etnografia em Movimento como Possibilidade para a Interpretação da Experiência Estética da Natureza. Cadernos de Pesquisa: Pensamento 
Educacional, v. 13, n. Especial: Educação Ambiental como espaço de luta e resistência: pesquisa, intervenção, formação e políticas públicas em debate, p. 184-203, 2018.

IARED, Valéria Ghisloti.; OLIVEIRA, Haydée Torres de O walking ethnography para a compreensão das interações corporais e multissensoriais na educação ambiental. Ambiente \& Sociedade, v. 20, n. 3, p. 99-116, 2017.

IARED, Valéria Ghisloti, OLIVEIRA, Haydée Torres de; PAYNE, Phillip. The aesthetic experience of nature and hermeneutic phenomenology. The Journal of Environmental Education, v. 47, p. 191-201, 2016.

INGOLD, Tim. Anthropology and/as Education. Routledge: Abingdon, 2017.

INGOLD, Tim. That's enough about ethnography!. Hau: Journal of Ethnographic Theory, vol. 4, n. 1, p. 383-395, 2014.

INGOLD, Tim. Being alive: essays on movement, knowledge and description. London: Routledge, 2011.

INGOLD, Tim. The perception of the environment: essays on livelihood, dwelling and skill. London: Routledge, 2000.

INGOLD, Tim; VERGUNST, Jo Lee (eds). Ways of walking: ethnography and practice of foot. Surrey: Ashgate Publishing, 2008.

JACKSON, Alecia; MAZZEI, Lisa. Thinking with theory in qualitative research: viewing data across multiple perspectives. New York: Routledge, 2012.

JICKLING, Bob. Sitting on an old grey stone: meditations on emotional understanding. In: McKENZIE, Marcia; HART, Paul; BAI, Heesoon; JICKLING, Bob. Fields of green: restorying culture, environment, and education. New Jersey: Hampton Press, 2009, p. 163 173.

KATZ, Jack. How Emotions Work. Chicago, University of Chicago Press, 2000.

LATHER, Patti; St. PIERRE, Elizabeth Adams. Post-qualitative research. International Journal of Qualitative Studies in Education, v. 26, n. 6, p. 629-633, 2013.

LOTZ-SISITKA, Heila; WALS, Arjen; KRONLID, David.; McGARRY, Dylan. Transformative, transgressive social learning: rethinking higher education pedagogy in times of systemic global dysfucntion. Current Opinion in Environmental Sustainability, v. 16, n. 73, p. 73-80, 2015.

McCORMACK, Derek. Refrains for moving bodies: experience and experiment in affective spaces. Durham: Duke University Press, 2013.

McKENZIE, Marcia. Affect theory and policy mobility: challenges and possibilities for critical policy research. Critical Studies in Education, v. 58, n. 2, p. 187-204, 2017.

MERLEAU-PONTY, Maurice. O Visível e o Invisível. São Paulo: Perspectiva, 2007. 
PAYNE, Phillip. What next? Post-critical materialisms in environmental education. The Journal of Environmental Education, v. 47, n. 2, p. 169-178, 2016.

MERLEAU-PONTY, Maurice. Vagabonding slowly: ecopedagogy, metaphors, figurations, and nomadic ethics. Canadian Journal of Environmental Education, v. 19, n. 1, p. 47-69, 2014.

MERLEAU-PONTY, Maurice. (Un)timely ecophenomelogical framings of environmental education research. In: STEVENSON, Robert; BRODY, Michael; DILLON, Justin; WALS, Arjen. International Handbook of Research on Environmental Education. New York: Routledge Publishers, 2013, p. 424-437.

MERLEAU-PONTY, Maurice. Framing research: conceptualization, contextualization, representation and legitizimation. Pesquisa em Educação Ambiental, v. 4, n. 2, p.49-77, 2005.

PAYNE, Phillip; RODRIGUES, Cae; CARVALHO, Isabel Cristina Moura; SANTOS, Laísa Maria Freire; AGUAYO, Claudio; IARED, Valéria Ghisloti. Affectivity in environmental education research. Pesquisa em Educação Ambiental, v. 13, n. Edição especial, p. 93-114, 2018.

PINK, Sarah. Doing sensory ethnography. London: SAGE, 2009.

ROBOTTOM, Ian.; HART, Paul. Research in environmental education: engaging the debate. Geelong,Victoria: Deakin University Press, 1993.

RODRIGUES, Cae. O vagabonding como estratégia pedagógica para a "desconstrução fenomenológica" em programas experienciais de educação ambiental. Educação em Revista, v. 31, n. 1, p. 303-327, 2015.

ROUDAVSKIA, Stanislav; McCORMACK, Jon. Post-anthropocentric creativity (Editorial). Digital creativity, v. 27, n.1, p. 3-6, 2016.

SHEETS-JOHNSTONE, Maxine. The corporeal turn: an interdisciplinary reader. Exeter: Imprint Press, 1999.

THRIFT, Nigel. Non-Represenational Theory: space, politics, affect. New York and London: Routledge, 2008.

WILLIGES. Flávio. O que o caminhar ensina sobre o bem-viver? Thoreau e o apelo da natureza. Cadernos Ihu Ideias. n. 271, v.16, p. 1-22. 2018. 